the first indications of the existence of the $\mathrm{C}^{\prime \prime}$ bodies and of the radiations from radium $D$. Between 1911 and 1915, with v. Baeyer and Hahn, she studied the groups of $\beta$-particles by the direct deviation method, showing that $\alpha$-ray as well as $\beta$-ray bodies give rise to such groups. After the Great War, Miss Meitner turned to the semicircular focusing method for the further study of the $\beta$-ray groups, regarding them now as secondary radiations associated with $\gamma$-ray emission, and was the first to maintain that in the process of disintegration the emission of radiation follows, rather than precedes, the emission of the particle. Experiments on the long range $\alpha$-particles, with Freitag, on the heating effect of the $\beta$-particles of radium $\mathbf{E}$, with Orthmann, and on the scattering of hard $\gamma$-rays, in collaboration with Hupfeld, occupied the years 1926-32. Since 1932 Miss Meitner has devoted her attention more and more to studies of nuclear transmutation and artificial radioactivity. With Hahn and Strassmann she has investigated particularly the complicated series of bodies obtained by bombarding uranium and thorium with neutrons.

\section{R.A.F. Long-distance Non-stop Record Flight}

THREE R.A.F. Vickers Wellesley bombers, two of which landed at Darwin, Northern Australia, at 4 a.m. (G.M.T.) on November 7, have broken the world's long-distance record, held by the Russian airmen who flew from Moscow to San Jacinto (California), a distance of 6,306 miles. The two Vickers machines covered a distance of 7,162 miles non-stop, from Ismailia to Darwin, while the third was forced to land at Koepang, Timor, 400 miles short of this, owing to lack of fuel. It afterwards completed the journey, arriving at Darwin at 7.36 a.m. Their speed averaged about 149 miles per hour, as compared with 102 miles per hour for the Russian record. The actual machines and their crews are a flight known as the Long Range Development Unit of the R.A.F., under the command of Wing-Commander Gayford, specially charged with the duties of investigating service problems associated with long-distance flying. Early in the flight, they flew in formation under the command of Squadron. Leader Kellett, but later they separated, the other two machines under Flight-Lieutenants Hogan and Combe each flying independently.

THE aircraft are standard Vickers Wellesleys as supplied as bombers to R.A.F. squadrons, modified for very long distance flights, principally having greater fuel tank capacity. They are cantilever monoplanes built with Vickers geodetic method of construction. The exceptional lightness of this structure allows a correspondingly large weight of fuel to be carried within the limitation of their maximum weight. They are fitted with retractable undercarriages, totally enclosed cabins and all other devices for reducing their drag to a minimum, thus keeping the power required as small as possible. The Bristol Pegasus XXII engine with its very low fuel consumption, adding to these refinements, has given the combination that makes a flight of this length possible. The machines were fitted with automatic pilots, which relieve the pilots of much of the necessity for actually holding the controls on a long fixed course. Sleeping accommodation was arranged in the cabins, and the other two members of each crew, navigator and wireless operator, were qualified pilots, able to control the aircraft when required.

\section{Planning for Defence}

A BRoadshert issued by PEP (Political and Economic Planning) entitled "Planning for Defence" directs attention to the necessity for fundamental thinking as to the values upon which the society that is being planned is to be based. The dangers of running a world by standards which are largely distorted for immediate material ends is clearly revealed by the events of September last, and realization of these dangers may well compel a reassessment of values, checking the drift towards opportunist materialism, and the evolution of a more explicit code of values on which the democracies and people in all countries who are not prepared to succumb to tem. porary illusions can take their stand as a basis for working towards a more tolerable human society. Simultaneously, specific thinking about the problems of a society and economy functioning under the shadow of war is urgently demanded and reinforces the case for eliminating waste in distributive services and elsewhere, the conservation of national resources, the adoption of economic operating units for public services and the rationalization or decentralization of some of the local government services or functions and staffs concentrated in London.

THE broadsheet suggests that such adjustment must be based on three principles: maximum efficiency (which in wartime might not coincide with efficiency in peace) ; the maintenance or even extension of ultimate democratic control, particularly in the economic sphere, whatever special powers might be needed; and the framing of emergency measures so far as possible in accord with the long-term needs of social and economic reconstruction. The importance of local self-reliance is stressed, for an educated democracy requires both resolute leadership and information on which to base its judgment and actions. It will be necessary to think out very carefully the respective functions of the local committee or council, of the executive officers who perform the local service and of the officer who represents the requirements of the central government. While the central government would require decentralization, many local services require larger operating areas for efficiency. The broadsheet further refers to the need for public information, for rationalizing transport and distribution, for keeping a balance between demands and the normal economic life of the com. munity. The structure of industry and especially the location of new plant present special problems, and, in regard to man power, one of the most serious problems is that of utilizing professional and technical workers. Nutrition policy and food control, land policy, the acquisition of development rights are other questions to which the broadsheet briefly directs attention. 